\title{
Bottleneck and Countermeasure of Information Literacy Education for Chinese Rural Residents - From the Perspective of "Beautiful Countryside"
}

\author{
Luo Xin \\ School of Business Administration, South China University of Technology, \\ Guangdong Guangzhou, China
}

Keywords: Information literacy; Rural residents education; Information construction; Quality education; Rural informatization

\begin{abstract}
Rural informatization mainly focuses on the construction of hardware infrastructure, which has made some achievements. However, the rural informatization is a comprehensive and systematic project, not only to increase the investment in the rural basic hardware facilities, but also to improve the self-cultivation of the villagers. Enhance the "soft power" of the villagers to cultivate a new generation of villagers with high information literacy. In order to promote the construction of "beautiful countryside" and improve the information literacy of villagers, this paper analyzes the bottleneck of rural information literacy education, and puts forward relevant countermeasures. This has practical significance for the realization of Chinese rural informatization construction.
\end{abstract}

\section{Introduction}

With the advent of the information age, information literacy has become an important factor restricting the individual's realization of his potential [1]. Agriculture also began to transform from traditional mode to information mode. The rural informationization around the hardware infrastructure and other aspects has made some achievements. However, rural informatization is a comprehensive and systematic project, not only to increase the infrastructure in rural areas such as hardware, but also should cultivate farmers themselves more, and improve peasants "soft power", create a new generation of farmers with higher information literacy. Farmers with higher information literacy can fundamentally promote rural informatization and new rural construction. The construction of rural informatization is the stage and carrier to improve the information literacy of farmers, and the information literacy of farmers is the fundamental way to promote the informatization construction in China, and they supplement each other.

"Beautiful Countryside" means to achieve "production development, wealthy life, polite phenomenon, clean and tidy appearance and democratic management", etc.. The concept is put forward in the fifth plenary session of the sixteenth communist party of China. Rural areas and rural population make up the majority of China. To achieve the goal of beautiful China proposed by the 18th CPC national congress, we must speed up the construction of beautiful countryside. The beautiful countryside is inseparable from the high scientific and cultural quality of the farmers.

However, according to the preliminary investigation, some villagers in the "Beautiful Countryside" of Guangzhou have a fairly low level of education, and the information knowledge of them is scarce. The villagers tend to get older, and the information ability is weak. The rural information infrastructure is backward and the information access is unitary. The information literacy training of the village committee is not enough. The construction of information service system in rural areas is not perfect, etc. The phenomenon shows that the villagers need to receive more information literacy education to enhance their scientific literacy. 
The term "rural residents information literacy" is derived from the concept of information literacy [2]. The concept of information literacy comes from the development and evolution of book retrieval skills. Our library workers must increase information literacy popularization and improve the information science literacy of villagers. Library scholars have carried out various researches on information literacy education. David James Brier explored drawing as an instructional method to teach information literacy [3]. Stephanie J. Graves explored collaborations between writing centers and libraries which create opportunities for providing information literacy intervention for students doing researched writing[4]. Kuan-nien Chen explored the essential features of information literacy; what role it should play in university library user education; and how programs can be best implemented [5]. Kate Zoellner examined the differences between first-year and senior undergraduate students' information literacy behaviors and experiences [6].

This article summarizes the preliminary investigation, analyses the bottleneck of information literacy education in Guangzhou "beautiful countryside", and puts forward the corresponding countermeasures, in order to promote the development of rural residents information literacy education.

\section{The bottleneck of Chinese rural residents information literacy education.}

2.1 The villagers have a low level education and lack of information knowledge. The extent of education is an important indicator of a person's quality. Education is the foundation, and the higher the education level, the stronger the ability to understand and accept new things. They have a deeper understanding of information knowledge and a strong willingness to pay for the valuable information, and also seek out the information they need in various ways. Vice versa. In agricultural production activities, the extent of education received by farmers reflects the level of their information literacy, and the understanding and acceptance of emerging information knowledge and modern information technology. From the preliminary investigation, the villagers accept the university education ratio is very low. This situation directly affects the information literacy ability of farmers, which leads to their poor sensitivity to information. They have very little information and are not willing to acquire valuable information. These situations seriously restrict farmers' ability to accept, handle, utilize and reproduce information. Therefore, our information literacy education still has a long way to go.

2.2 Rural residents tend to become older and have less information ability. The age structure of the villagers also greatly influences the information awareness and acceptance. For young people, their knowledge system is more advanced, their vision is more open, and they accept new things to be conscious and competent. They have the will to interpret and experience. Older people, by contrast, are less competent than young people. At present, rural residents in China are becoming older, and a large proportion of the residents are women and old people. They have long been "isolated", especially in information knowledge and modern information technology, and have poor ability to learn and master modern information technology. These restrict the improvement of the villagers' overall information quality.

2.3 Rural information infrastructure lags behind, and the villagers obtain information channels too monotonous. Due to the attention of the state, the construction of rural infrastructure has made some achievements in recent years. But the rural area of China is vast, and it is not enough to rely on the state's fiscal input, which directly restricts the development of rural informatization construction. According to the literature analysis, about 26 percent of respondents believed that public cultural infrastructure such as library and reading room should be established in the countryside. Eighteen percent of the respondents said they needed a mechanism in rural areas to 
facilitate farmers' access to information. Forty percent of people believe that technology can be organized regularly to get information into the field. The backward of information infrastructure directly restricts the ability of farmers to obtain information. The main reasons for the weak information acquisition ability of farmers are: first, the communication facilities in mountainous areas are very backward. Rural network coverage is poor and it is also the main reason for many families not buy computers. The second is the unitary approach to information acquisition. Most of the information obtained by farmers depends mainly on the exchanges between friends and relatives, the information released by the village officials and watching TV programs.

2.4 The village committee's information literacy education activity is not enough. In the process of agricultural informationization construction, the village committee is the most important basic-level organization. But the leadership of the village committee is not enough, and the role of the government has not been given full play. First, the organization and management functions of the village committee are gradually weakened. In the process of agricultural production and life, farmers have high management autonomy due to the reasons of the long-term small-scale peasant economic system. The independent production mode, which focuses on family and individual management, has weakened the function of village organization. The guidance, control and education function of the village committee have been greatly weakened. It causes the village committee to organize the farmer's information literacy training difficulties in the rural areas, which hinders the improvement of the farmers' information literacy, and the promotion of rural informatization construction. Second, the village committee is not enough attention to rural informatization construction. Third, infrastructure is incomplete and weak. The construction of basic training facilities such as remote education is not perfect, and the village organizations are powerless. Even if the village committee wants to organize the peasants to study, it is impossible to complete because of the limitation of hardware facilities, which makes it difficult to improve the information literacy of farmers.

2.5 The rapid development of informatization contradicts the information literacy of the villagers. Now, more kinds of information are present and passed in electronic form, such as journal databases, e-books and news reports. With the development of information technology, agriculture also began to transform from traditional agriculture to information agriculture. Information technology in many developed countries has been developed in agriculture, and developing countries are also looking for the appropriate rural informatization way. Now, it is necessary to get timely information from the improvement and optimization of planting technology, the prevention and control of diseases or pests, product packaging and sales. Agriculture did not need such rapid information acquisition in the past as it is now. But the primitive agriculture was adapted to the social environment at that time, at the information acquisition speed. And modern agriculture can only obtain the ideal development by adapting to the current information acquisition speed.

\section{Countermeasures for the information literacy of Chinese rural residents education.}

The development of information literacy education is the most fundamental way to realize the goal of rural informatization construction. The basic idea of information literacy education should serve this purpose. Rural informatization construction is an important way to improve rural material condition, and it determines the basic trend of education. With the implementation of reform in rural areas, farmers' income level has been gradually raised, and farmers have been able to meet the basic needs of their material subsistence through income. While, spiritual improvement is a momentous way for farmers to further create material wealth and enjoy material wealth. The lack of information literacy education prevents farmers from using information to understand the outside world. With 
the continuous improvement of economic conditions, the cultivation of information literacy has become increasingly prominent in rural informatization construction. After drawing on relevant experiences from abroad, the countermeasures of education of information literacy in rural areas are summarized in order to provide some Suggestions for them [7][8].

3.1 Coordinate the village committees and the education institutions. The government plays an important role in the formulation and implementation of policy. This determines that the government's policies and administrative actions also play a crucial role in the construction of rural informatization. The government should formulate education contents according to the economic conditions, education degree and information demand characteristics of local farmers. At the same time, the local education institutions should earnestly implement the relevant policies formulated by the government, and educate farmers to acquire, maintain and utilize different types of information to promote the construction of rural informatization. The government should increase investment in rural infrastructure construction to ensure the education institutions to realize education policy through class teaching, network teaching, remote education resources sharing.

3.2 Joint educational institutions and rural autonomous organizations. In China, rural autonomous organizations and education institutions need to jointly carry out the farmers information literacy education to promote the construction of rural informatization. From the current situation, the cultivation consciousness of farmers' information literacy is weak, which hinders the development of education work in the countryside, thus affecting the development of rural economy. The education organizations need to cooperate with rural autonomous organizations, so as to eliminate obstacles to the rural informatization construction by improving the information literacy level of farmers. The education institutions in rural areas cultivate high level agricultural information talents mainly through orientation training or commissions. These talents are the leaders in the construction of rural informatization. To strengthen the information knowledge, ability and technology of rural grassroots cadres, especially the village officials and cadres of rural cadres. We will improve the mechanism for cultivating rural talents, and the government will organize rural application talents to go to the countryside more often. The rural autonomous organizations cooperate with educational institutions to make the farmers realize the importance of information literacy education, so as to actively participate in it.

3.3 Develop multi-level rural information literacy education. According to psychologist Abraham Maslow, physiology, socialization, respect and freedom constitute the most basic psychological needs of humanity. The higher of the demand, the more fundamental and important. From the perspective of functionalism, information knowledge, information ability, information morality and information consciousness are four aspects of information literacy. They play a different role in the process of meet the farmers' psychological needs. Specifically, information awareness and information ethics are designed to prevent information violations about themselves or others. In this way, we can ensure that the social evaluation of ourselves and others is just, and private lives are kept secret, which is closely related to the realization of the peasants' dignity and freedom. In contrast, information ability and information knowledge learning mainly aims to help farmers get information transmission and use related knowledge, and help farmers meet the development of personality freedom. Specifically, rural information literacy education should be divided into basic information literacy education and high-level information literacy education.

\section{Conclusions}

Rural informatization mainly focuses on the construction of hardware infrastructure, which has made some achievements. However, the rural informatization is a comprehensive and systematic 
project, not only to increase the investment in the rural basic hardware facilities, but also to improve the self-cultivation of the villagers themselves. Enhance the "soft power" of the villagers to cultivate a new generation of villagers with high information literacy. The construction of rural informatization is the stage and carrier to improve the information literacy of farmers, and improving the information literacy of farmers is the fundamental way to promote the construction of rural informatization, and they complement each other.

In China, there are still some practical problems in the rural information literacy education, such as the government's unclear responsibilities, the lack of information talents and the imperfect information resources guarantee mechanism. At the same time, the majority of farmers lack the understanding of information literacy education, they have weak information awareness, low information ability, lack of information ethics and information knowledge. In the environment of rural informatization construction, information collection and circulation speed up. Because of the low information literacy of farmers, some information security problems are brought to them in the process of finding, identifying and using information. Based on such practical problems, this paper analyzes the bottleneck of rural information literacy education and puts forward relevant countermeasures in order to build a "beautiful countryside". This also has important practical significance for the realization of Chinese rural informatization construction.

\section{Acknowledgments}

The research is financially supported by Guangzhou Association for Science\& Technology of China (Grant No. K2017020201002).

\section{References}

[1] Nikolas Leichner, Johannes Peter, Anne-Kathrin Mayer, Günter Krampen, (2013) "Assessing information literacy among German psychology students", Reference Services Review, Vol. 41 Issue: 4, pp.660-674.

[2] Dr Jane Secker, (2012) "Teaching Information Literacy Online", Program, Vol. 46 Issue: 2, pp.281-283.

[3] David James Brier, Vickery Kaye Lebbin, (2015) "Learning information literacy through drawing", Reference Services Review, Vol. 43 Issue: 1, pp.45-67.

[4] Stephanie J. Graves, Kathy Christie Anders, Valerie M. Balester, (2017) "Mining writing center data for information literacy practices", Reference Services Review, Vol. 45 Issue: 1, pp.100-116,

[5] Kuan-nien Chen, Pei-chun Lin, (2011) "Information literacy in university library user education", Aslib Proceedings, Vol. 63 Issue: 4, pp.399-418.

[6] Kate Zoellner, (2016) "Exploring undergraduate student experiences with information literacy", Performance Measurement and Metrics, Vol. 17 Issue: 3, pp.241-251.

[7] Arthur Winzenried, (2011) "Practising Information Literacy: Bringing Theories of Learning, Practice and Information Literacy Together", Library Review, Vol. 60 Issue: 1, pp.90-91.

[8] Meredith Farkas, (2012) "Participatory technologies, pedagogy 2.0 and information literacy", Library Hi Tech, Vol. 30 Issue: 1, pp.82-94, 